\title{
Correlation between beer consumption per capita and number of active breweries in the selected European countries
}

\author{
Xénia Szarková ${ }^{*}$ and Radovan Savov ${ }^{1}$ \\ ${ }^{1}$ Slovak University of Agriculture in Nitra, Faculty of Economics and Management, Tr. A.Hlinku, 2, \\ 94976 Nitra, Slovakia
}

\begin{abstract}
Research background: Craft beer is becoming one of the most popular alcoholic beverages globally, during the last decade. Additionally, industrial beer producers started to offer some special craft beer types that prove the rising demand for differentiated beer products.

Purpose of the article: Since one of our common fields of interest is the development of the brewing industry, we intended to provide an overview of a recent trend in this sector, which is the expansion of craft breweries. As the data reveals, this trend has been present in various European countries, as well. Therefore, the purpose of this paper is to show that the trend of craft brewing is present in countries with strong brewing history such as Belgium, the Czech Republic, or Germany, and in those countries which are not considered as typical beer producers because of their location and culture.

Methods: The information provided in this paper was retrieved mainly from scientific papers that focus on the brewing industry and the craft beer revolution. To be able to offer transparent and understandable results, we retrieved data from the reports of Brewers of Europe, which is a European non-profit association. Therefore, the research methods used are the comparison of quantitative data and correlation.

Findings \& Value added: The paper provides an overview of the expanding craft beer industry in the selected European countries and how strong the relation between beer consumption per capita (l) and number of active breweries is.
\end{abstract}

Keywords: globalization, brewing industry, craft beer

JEL Classification: $D 11, F 60, L 66$,

\footnotetext{
* Corresponding author: xszarkovax@uniag.sk
} 


\section{Introduction}

Consumption of beer is part of the European culture and gastronomy that finds its roots back in the Roman era (Swinnen et al., 2011). When it comes to the European alcoholic beverage preferences, it can be divided mainly into wine, beer, or spirits based on the location. On the other hand, during the past decades, there have been significant changes in the structure of the brewing industry, that were caused by globalization.

One of the effects was the rapid expansion of craft breweries around Europe, also in countries that were not considered as strong beer producers, such as France, Italy, and Spain (Wojtyra et al., 2020). The other important factor was the empowerment of industrial breweries that was supported by organizational, marketing, and technological improvements which enabled these organizations to minimize costs and maximize profits. Since all these improvements were present on the global market, a dominant oligopolistic market segment was created (Hunculak, 2004). The high concentration of the alcohol industry is controlled by a few companies, that is true also for the brewing sector since about $50 \%$ of the global market share is in the hand of five multinationals (Jernigan, 2009). On the other hand, several researchers highlighted the significance of craft products, such as Johnson (2009) or Micelli (2011), who emphasized how craft production can support competitiveness in the global market. Gradually, beer produced by giant multinationals became homogenized and consumers became open-minded to try new tastes with tradition and uniqueness.

Several studies analyze various aspects of alcohol consumption. Most of them conclude that the choice of beverage is mainly determined by cultural, circumstantial, and psychological factors (McCluskey and Shreay, 2011). As opposed to other alcoholic beverages, beer is perceived by consumers as an everyday beverage that can be consumed also during everyday occasions like watching TV or relaxing after work (Pettigrew and Charters, 2006).

\subsection{Countries with a strong brewing tradition}

Europe has a longstanding beer-producing history and some countries are well-known for this commodity. While craft breweries are experiencing a significant expansion, the beer preferences are still culturally specific and are still changing based on various factors (McCluskey and Shreay, 2012). For example, Germany is known for beer production, and it seems that the consumers still prefer regional products, and they have the knowledge of the types. Based on research, German consumers can be divided into three main groups. "Pils" breweries are able to sell their beer for a cheaper price that means also that it is consumed mostly by price-sensitive consumers, who belong to the first group. The second kind of consumer is younger, richer, and educated who prefer organic and special types of beer for a little higher price. Furthermore, there are more conservative beer drinkers who prefer beer with a higher alcohol percentage (Meyerding et al., 2019). The German craft brewing expansion is less dynamic as opposed to other European countries. New craft beer businesses are less common arguably because of the low market concentration (Depenbusch et al., 2018). In the case of Central and Eastern Europe, the main transition towards an open economy and international trade started in 1989 that lead to a higher standard of living and income growth that enabled the increase in beer consumption (Poelmans and Swinnen, 2011). When it comes to this region, there was a significant development in the brewing industry between 2000 - 2010, where the number of breweries increased from 54 to 151 during a tenyear period (Březinová et al. 2019). 


\subsection{Countries oriented on the production of different alcoholic beverages than beer}

In the $21^{\text {st }}$ century some European countries are strongly associated with wine but in fact, in the past also those regions were producing beer before the Roman Empire was leading (Nelson, 2005). That is why beer production in France, Spain, or Italy is not a completely new phenomenon. While considering Italy's brewing tradition, it was not considered as a typical producer of beer until the late 1980s, when hundreds of new craft breweries started to emerge on the market. There has been a change in consumer preferences since in 1980 the beer consumption per capita was 16.71 and in 2012 it has increased to 29.51 , which caused the significant growth in beer production between this period from 8,569,096 hl to $13,482,000 \mathrm{hl}$ (Garavaglia, 2018). Even though the absence of historic brewing tradition can be considered as a negative characteristic of the Italian brewing industry, the number of microbreweries has rapidly increased from 206 to 862 between the years 2008 and 2018 (Sforzi and Colombo, 2020). Nowadays, the brewing sector has a major impact on the Italian economy and enterprises are focusing on sustainability, innovations, and responsible drinking. After the economic crisis the industry experiences some changes, since the consumption of cheap private-label beers has increased, premium beers have decreased and the unique craft beers have increased the market share, that is the effect of the curiosity of consumers (Berkhout, 2014).

The rising popularity of beer can appear only in a particular region or by one gender. For example, in the case of Spain women in Murcia prefer beer as the main source of alcoholic beverage (Sieri et al. 2002). Also, people's inclinations can be selected based on certain social events and occasions. According to research by Silva et al. (2016), Spanish and Dutch respondents consider beer as an appropriate beverage for socialization or as a thirst quencher, while wine was associated with special moments and celebrations. They also associated emotions like "adventurous, energetic and free" to beer, and "calming, comforted and fulfilled" to wine.

\section{Methods}

Besides all the theoretical evidence, in this part, there is data prepared that provides an overview of the expansion of the brewing industry in the selected European countries that differ from each other based on the culture, location, and natural resources. Therefore, we decided to observe countries with rich brewing traditions, such as Belgium, Germany, and the Czech Republic, and contrarily countries with relatively no brewing history such as Italy, Spain, and France. Since precise data that contains separate information on industrial and craft brewing is not uncovered yet, we analyzed the brewing industry, as a whole. On the other hand, globalization caused various consolidations of the giant multinationals which means that the rapid expansion in the number of existing breweries can be mainly referred to as the craft brewing sector (Wojtyra et al., 2020). To provide the relevant information the main method used is the comparison and the data we retrieved evidence is from the yearly reports of Brewers of Europe, which is a non-profit association focusing on the European brewing industry. In the second part, we use correlation coefficients that indicate the strength of two variables, in our case beer consumption per capita (1) and number of active breweries (Weisstein, 2006). 


\section{Results and Discussions}

Since the "boom" of microbreweries is present all around the world, we wanted to highlight some European countries with unique cultures to prove that globalization affected the choices made by customers. For the comparison, we selected countries with long brewing traditions and countries that are rather well-known for the production of other alcoholic beverages.

Table 1. Number of existing breweries in the selected European countries between $2010-2019$.

\begin{tabular}{|l|l|l|l|l|l|l|l|l|l|l|l|}
\hline & $\mathbf{2 0 1 0}$ & $\mathbf{2 0 1 1}$ & $\mathbf{2 0 1 2}$ & $\mathbf{2 0 1 3}$ & $\mathbf{2 0 1 4}$ & $\mathbf{2 0 1 5}$ & $\mathbf{2 0 1 6}$ & $\mathbf{2 0 1 7}$ & $\mathbf{2 0 1 8}$ & $\mathbf{2 0 1 9}$ & $\boldsymbol{\Delta} \%$ \\
\hline Belgium & 135 & 123 & 150 & 160 & 168 & 199 & 224 & 261 & 304 & 340 & 151.85 \\
\hline Czech Republic & 151 & 191 & 213 & 308 & 338 & 390 & 398 & 450 & 488 & 617 & 308.61 \\
\hline France & 387 & 442 & 503 & 580 & 663 & 793 & 950 & 1100 & 1600 & 2200 & 468.5 \\
\hline Germany & 1333 & 1347 & 1340 & 1349 & 1352 & 1388 & 1408 & 1492 & 1539 & 1548 & 16.13 \\
\hline Italy & 308 & 391 & 421 & 509 & 599 & 688 & 757 & 868 & 874 & 853 & 176.95 \\
\hline Spain & 65 & 88 & 132 & 221 & 332 & 427 & 483 & 521 & 538 & 519 & 321.05 \\
\hline
\end{tabular}

Source: own evaluation (2021)

In Table 1. the emergence of breweries and the percentage change between $2010-2019$ are provided. It is obvious that the craft beer revolution was present in all the observed countries during the selected period. The most significant increase was noted France (468.5\%) and Spain (321.05\%). Even though the Czech Republic has a powerful brewing history, there was a $308.61 \%$ rise in the number of active breweries. Furthermore, there was $151.85 \%$ increase in Belgium, $16.13 \%$ in Germany, and $176.95 \%$ in Italy.

Table 2. Beer consumption (1000 000 hl) in the selected European countries between 2010 2019.

\begin{tabular}{|l|l|l|l|l|l|l|l|l|l|l|l|}
\hline & $\mathbf{2 0 1 0}$ & $\mathbf{2 0 1 1}$ & $\mathbf{2 0 1 2}$ & $\mathbf{2 0 1 3}$ & $\mathbf{2 0 1 4}$ & $\mathbf{2 0 1 5}$ & $\mathbf{2 0 1 6}$ & $\mathbf{2 0 1 7}$ & $\mathbf{2 0 1 8}$ & $\mathbf{2 0 1 9}$ & $\boldsymbol{\Delta} \%$ \\
\hline Belgium & 8.44 & 8.57 & 8.23 & 8.09 & 8.10 & 7.95 & 7.69 & 70.01 & 7.02 & 7.04 & -16.6 \\
\hline $\begin{array}{l}\text { Czech } \\
\text { Republic }\end{array}$ & 15.57 & 15.54 & 15.45 & 15.80 & 15.77 & 15.70 & 15.88 & 15.52 & 15.94 & 16.08 & 3.31 \\
\hline France & 19.73 & 20.00 & 19.94 & 19.42 & 19.96 & 20.60 & 21.19 & 21.50 & 23.50 & 23.60 & 19.61 \\
\hline Germany & 87.87 & 87.66 & 86.28 & 85.89 & 86.51 & 86.02 & 85.53 & 83.58 & 84.65 & 82.93 & -5.62 \\
\hline Italy & 17.25 & 17.72 & 17.46 & 17.54 & 17.76 & 18.91 & 19.03 & 19.68 & 20.32 & 20.86 & 20.94 \\
\hline Spain & 35.20 & 35.23 & 35.11 & 35.21 & 36.32 & 37.46 & 38.51 & 39.37 & 39.95 & 41.30 & 17.34 \\
\hline
\end{tabular}

Source: own evaluation (2021) 
Next, in Table 2. beer consumption is presented. When it comes to the traditional beer producer countries, the total consumption of beer decreased in Belgium by $16.64 \%$, in Germany by $5.62 \%$ in the Czech Republic slightly increased by $3.31 \%$. Furthermore, in countries that are oriented on other alcoholic beverages this value increased, specifically in France by $19.61 \%$, in Italy by $20.94 \%$, and in Spain by 17.34 . This is probably the effect of open markets where consumers are able to try products that are not typical for their own countries and are anytime able to purchase those foreign products.

Table 3. Correlation between beer consumption per capita (1) and the number of active breweries in the selected European countries.

\begin{tabular}{|l|l|l|l|l|l|}
\hline Belgium & $\begin{array}{l}\text { Czech } \\
\text { Republic }\end{array}$ & Germany & Spain & France & Italy \\
\hline-0.92 & -0.58 & -0.95 & 0.08 & 0.81 & 0.86 \\
\hline
\end{tabular}

Source: own evaluation (2021)

In Table 3. we illustrate the correlation between beer consumption per capita (1) and the number of active breweries between the period 2009-2019. As an example, we observed countries with rich brewing history (Belgium, the Czech Republic, and Germany) and countries that are contrarily strong in other alcoholic beverage production (Spain, France and Italy). The results are interesting when considering the changes in consumer preferences based on the different regions and cultures of Europe. Based on the analysis, in the case of countries that are in general considered as traditional beer producers, there is a negative correlation $(-0.92,-0.58,-0.95)$ and in the case of producers of other alcoholic beverages, there is a strong positive correlation $(0.08,0.81,0.86)$. Based on the correlation coefficient, when the number of active breweries increase, the beer consumption per capita decreases in countries with strong brewing history and increases in countries that are oriented on different alcoholic beverages production. Since the correlation coefficient is almost zero in the case of Spain, we can consider that there is no relation between the two selected variables.

This can be interpreted in different ways. Since the food and beverage market in Europe is quite globalized, consumers have the opportunity to try new products that are not typical for their culture or location. This trend can explain why both the beer consumption per capita (l) and the number of active breweries are simultaneously increasing in the countries that typically produce other alcoholic beverages. On the other hand, the strong brewing countries are able to focus on the export of beer products and consumers are open to trying new craft beer products or others.

\section{Conclusions}

It can be concluded that globalization has a considerable effect on the changes in consumer preferences. The same is true for beer products that decades ago were most beloved mainly in typical beer-producing countries in Europe. Conversely, the curiosity of consumers living in the $21^{\text {st }}$ century has led small producers in various European countries to expand their own production of craft beer even in locations that were not famous for this beverage before. For example, Italy can be considered as one of the richest countries in culture, gastronomy, and agrotourism, but they had not focused on beer production until the $1980 \mathrm{~s}$. Together with other European countries that are historically strong in the production of different alcoholic products, such as France or Spain, they started to develop craft beer production, as well. As it resulted in our research, that is a response to the global trend of 
craft products and the changes in modern consumers' preferences. Even though countries with rich brewing traditions can experience the same effect with other food and beverage products, the number of new microbreweries is still increasing there, as well. Consumers prefer differentiated products and support the traditional brewing sector. Since this trend can be observed throughout the last decades worldwide, also industrial producers of beer reacted by the introduction of differentiated beer products on the international market. This can lead to various economic outcomes and further changes in consumer preferences. Therefore, this paper leaves a number of questions connected to the development of the brewing industry unanswered that we would like to unfold in the near future.

\section{Acknowledgments}

This work was supported by the Scientific Grant Agency of the Ministry of Education of the Slovak Republic (ME SR) and the Slovak Academy of Sciences (SAS) under the contract No. VEGA-1/0525/21.

\section{References}

1. Aquilani, B., Laureti, T., Poponi, S., \& Secondi, L. (2015). Beer choice and consumption determinants when craft beers are tasted: An exploratory study of consumer preferences. Food quality and preference, 41, 214-224.

2. Berkhout, B., Bertling, L., Bleeker, Y., de Wit (EY), W., Kruis, G., Stokkel, R., Theuws, R. (2020). The Contribution made by Beer to the European Economy. Full Report December 2020. A report commissioned by The Brewers of Europe and conducted by Regioplan Policy Research and EY. Retrieved from: https://brewersofeurope.org/uploads/mycms-

files/documents/publications/2020/contribution-made-by-beer-to-EU-economy2020.pdf.

3. Brezinová, M., Havelka, Z., \& Bartoš, P. (2019). Marketing communication in beer industry in the Czech Republic with respect to minibreweries. Kvasny prumysl, 65, 612 .

4. Depenbusch, L.; Ehrich, M.; Pfizenmaier, U. Craft Beer in Germany. New Entries in a Challenging Beer Market. In Economic Perspectives on Craft Beer; Garavaglia, C., Swinnen, J., Eds.; Springer: Basel, Switzerland, 2018; pp. 183-210.

5. Garavaglia, C. (2018). The birth and diffusion of craft breweries in Italy. In Economic Perspectives on Craft Beer (pp. 229-258). Palgrave Macmillan, Cham.

6. Garavaglia, C., \& Mussini, M. (2020). What Is Craft?-An Empirical Analysis of Consumer Preferences for Craft Beer in Italy. Modern Economy, 11(6), 1195-1208.

7. Hunculak, M. (2004). The spatial consequences of globalization on the European brewing industry. Prace geograficzne, 114, 23-35.

8. Jernigan, D. H. (2009). The global alcohol industry: an overview. Addiction, 104, 6-12.

9. Johnson, M. W. (2009). Work we can believe in. Why manual work is making a comeback. Financial Times, June, 27-28.

10. McCluskey, J., Shreay, S., 2012. Culture and Beer Preferences. In The Economics of Beer, Swinnen, J.F.M. (eds.). Oxford Scholarship Online. 〈https://doi.org/10.1093/ acprof:oso/9780199693801.001.0001).

11. Meyerding, S. G., Bauchrowitz, A., \& Lehberger, M. (2019). Consumer preferences for beer attributes in Germany: A conjoint and latent class approach. Journal of Retailing and Consumer Services, 47, 229-240.

12. Micelli, S. (2011). Futuro artigiano: l'innovazione nelle mani degli italiani. Marsilio Editori Spa. 
13. "Nelson, M. (2005). The Barbarian's Beverage: A History of Beer in Ancient Europe. London and New York: Routledge."

14. Pettigrew, S. and Charters, S. (2006). Consumers' expectations of food and alcohol pairing. Br. Food J. 108:169-180.

15. Poelmans, E., \& Swinnen, J. F. M. (2011a). A brief economic history of beer. In J. F. M. Swinnen (Ed.), The economics of beer. Oxford: Oxford University Press.

16. Sester, C., Dacremont, C., Deroy, O., \& Valentin, D. (2013). Investigating consumers' representations of beers through a free association task: A comparison between packaging and blind conditions. Food Quality and Preference, 28(2), 475-483.

17. Sforzi, J., \& Colombo, L. A. (2020). New Opportunities for Work Integration in Rural Areas: The 'Social Flavour' of Craft Beer in Italy. Sustainability, 12(16), 6351.

18. Sieri, S., Agudo, A., Kesse, E., Klipstein-Grobusch, K., San-José, B., Welch, A. A., . . . Slimani, N. (2002). Patterns of alcohol consumption in 10 european countries participating in the european prospective investigation into cancer and nutrition (EPIC) project. Public Health Nutrition, 5(6 B), 1287-1296. doi:10.1079/PHN2002405.

19. Silva, A. P., Jager, G., van Bommel, R., van Zyl, H., Voss, H. P., Hogg, T., ... \& de Graaf, C. (2016). Functional or emotional? How Dutch and Portuguese conceptualise beer, wine and non-alcoholic beer consumption. Food quality and preference, 49, 5465 .

20. Weisstein, E. W. (2006). Correlation coefficient. https://mathworld. wolfram. com/.

21. Wojtyra, B., Kossowski, T. M., Březinová, M., Savov, R., \& Lančarič, D. (2020). Geography of craft breweries in Central Europe: Location factors and the spatial dependence effect. Applied Geography, 124, 102325. 